\title{
Uma abordagem utilizando LEGO Mindstorms Education EV3 para verificar o desempenho acadêmico dos estudantes do Instituto Federal de Educação, Ciência e Tecnologia de Mato Grosso do Sul do Câmpus Aquidauana
}

\author{
Leandro de Jesus ${ }^{1}$, Marcia F. Cristaldo ${ }^{1}$ \\ ${ }^{1}$ Instituto Federal de Educação, Ciência e Tecnologia de Mato Grosso do Sul - Câmpus \\ Aquidauana (IFMS) \\ Caixa Postal 116 - 79.200-000 - Aquidauana - MS - Brazil \\ \{leandro.jesus, marcia.cristaldo\} @ifms.edu.br
}

\begin{abstract}
This article discusses the use of LEGO Mindstorms Education EV3 to verify the academic performance of students at the Federal Institute of Education, Science and Technology of Mato Grosso do Sul Campus Aquidauana. Thinking about these performance factors this learning project used the Olympics as robotic strategy to introduce students to technologies and concepts. In this paper we describe our approach and present the results in detail, assessing the adequacy of the greatest motivational use of a robot and also the real fulfillment of the other requirements of the discipline as learning algorithm, decrease dependency of disciplines and improvement in grades.
\end{abstract}

Resumo. Este artigo aborda o uso do LEGO Mindstorms Education EV3 para verificar o desempenho acadêmico dos estudantes do Instituto Federal de Educação, Ciência e Tecnologia de Mato Grosso do Sul do Câmpus Aquidauana. Pensando nesses fatores de desempenho de aprendizagem esse projeto utilizou as olimpíadas de robótica como estratégia para introduzir os estudantes às tecnologias e seus conceitos. Neste artigo descrevemos a nossa abordagem e apresentamos em detalhes os resultados, que avaliam a adequação motivacional maior do uso de um robô e também o cumprimento real dos outros requisitos como aprendizagem da disciplina de algoritmo, diminuição de dependência de disciplinas e melhoria nas notas.

\section{INTRODUÇÃO}

Estudos indicam que a robótica fornece uma fonte de energia que pode ser usada para motivar a aprendizagem dos estudantes. Pesquisas realizadas mostram um ganho de aprendizagem com o uso de robótica (OLIVER, 2010). Na realização de revisão bibliográfica, pode-se ver que estes ganhos estão concentrados principalmente em dois aspectos: (i) contribuições sobre o aprendizagem de conceitos/disciplinas, e (ii) o desenvolvimento de competências.

Nesse sentido, houve uma iniciativa de incluir as olimpíadas científicas de robótica no Instituto Federal de Educação, Ciência e Tecnologia de Mato Grosso do Sul - IFMS, Câmpus Aquidauana, que se mostrou interessante para a popularização e difusão da ciência e tecnologia junto aos jovens da região, sendo essa tecnologia utilizada em 
praticamente todo o mundo. Pensando nesses fatores de desempenho de aprendizagem esse projeto utilizou as olimpíadas de robótica como estratégia para introduzir os estudantes às tecnologias e seus conceitos.

Neste contexto, foi criado o grupo Group of Robotics and EducAtional Technologies GREAT, que iniciou em 2013 com atividades de ensino na área da computação e áreas comuns, visando o desenvolvimento do raciocínio lógico, do trabalho em equipe e outras habilidades e competências relacionadas às olimpíadas científicas, em especial a Olimpíada Brasileira de Robótica (OBR).

O Objetivo do artigo é verificar a metodologia utilizada para apoio ao processo de aprendizagem - através da utilização da competição de robótica - as contribuições deste processo na potencializarão de aprendizagens nas áreas de Ciências e Algoritmos do Ensino Médio Integrado de Informática do Câmpus Aquidauana IFMS.

Neste artigo é descrita a abordagem e são apresentados alguns resultados, para avaliar a adequação motivacional maior do uso de um robô com os estudantes e também o cumprimento real dos outros requisitos como aprendizagem da disciplina de algoritmo, diminuição de dependência de disciplinas e melhoria nas notas.

\section{Desenvolvimento}

Pensando no crescimento da área, a robótica pedagógica começou a ser uma solução inovadora, e as instituições de educação estão incluindo nos seus currículos, desde o ensino primário à universidade MILLER et. al,. (2008). Nesse sentido, foi realizado inicialmente uma revisão bibliográfica para verificar qual o tratamento didáticopedagógico realizado com projetos de tecnologias educacionais, explorando o potencial da robótica nas escolas de ensino básico e médio.

Até o momento o estudo mostrou que, muitas plataformas na área de robótica educacionais estão surgindo, dando aos professores a chance de escolher o mais adequado para os seus fins de ensino. O estudo utilizou as obras de Oliver et. al., (2010); Summet et al., (2009); Touretzky; Tira-Thompson, (2010) em Ciência da Computação e Engenharia de Computação, e Ecebot MAHER et al.,(2005) e Harbour; Hummel, (2010). Quanto às ferramentas educacionais remotas, existem várias soluções, como as descritas em Khamis et. al., (2003), relacionados com a robótica.

As pesquisas mostram que alguns estudiosos da educação, como Papert (1993) acredita que as atividades de robótica tem um enorme potencial para melhorar o ensino em sala de aula.

Foi observada na literatura, que a maioria das aplicações da robótica na educação se concentrou principalmente no apoio ao ensino de disciplinas que estão intimamente relacionados com a área de robótica, como programação de robôs, a construção do robô ou mecatrônica. Dessa maneira, os autores resolveram aplicar para ambientes educacionais, realizando mini cursos, palestras e desafiando os estudantes a construção de projetos individuais, até a participação da competição, onde se observou maior interesse dos estudantes. 


\section{Metodologia}

Este trabalho pode ser dividido em três etapas: preparação do material didático do curso LEGO Mindstorms Education EV3, seleção e capacitação dos estudantes, análise dos resultados. A seguir será detalhada toda a metodologia desenvolvida nesse projeto.

\subsection{Preparação do material didático do curso LEGO Mindstorms Education EV3}

Esta etapa consistiu na elaboração de uma apostila ilustrativa, baseada no material bibliográfico disponível para consulta na internet, biblioteca e fontes acadêmicas. A apostila abordou os seguintes temas: conhecimentos básicos de robótica, instalação dos softwares LEGO Mindstorms Education EV3.

\subsection{Seleção e capacitação dos estudantes}

Houve um edital interno para os estudantes do ensino médio integrado em Informática, sendo o pré-requisito utilizado para entrar no grupo da competição foi o conhecimento na disciplina de algoritmos oferecido no primeiro semestre do curso, sendo observado o interesse e as notas das disciplinas de algoritmos, matemática e física. Para capacitação inicialmente foi oferecido mini curso para os estudantes selecionados que incluía uma parte teórica, sendo a explicação da orientação de cada exercício LEGO e uma palestra final aberta para discutir a sua solução, aplicando um trabalho prático em pequenos grupos ( 2 pessoas), podendo o professor ajudar, se necessário. A duração foi de 4 meses, e posteriormente cada grupo sendo 6 estudantes inicialmente, iniciaram um estudo em até 3 estudantes, para montagem e programação de um carro para competição de robótica. Os professores acompanharam todo o processo desde a montagem até a programação e treinamento para competição.

\subsection{Análise dos resultados}

Ao final do projeto foi preparado um questionário para os estudantes. No questionário foram levantados dados relativos à opinião dos participantes quanto à metodologia utilizada ao longo das aulas projeto de robótica, ao projeto e a importância dos conhecimentos adquiridos nesse projeto para a vida dos estudantes. Outros pontos analisados no primeiro questionário foram acerca da melhoria no desempenho escolar dos estudantes e o aprimoramento de seus conhecimentos em robótica e nas outras áreas de exatas.

\section{Resultados}

Para atingir o objetivo para competição, eles tiveram que construir e programar um robô para atuar num ambiente simulado de resgate num desastre. $\mathrm{O}$ robô deveria detectar e superar diversos tipos de obstáculos, encontrar a vítima, representada por uma latinha de refrigerante, e proceder com o seu resgate, sem a utilização de nenhum controle remoto. Para desenvolver mecanismos que possibilitem a autonomia do robô, os estudantes utilizaram diversos sensores e elaboraram um programa computacional de controle. No caso da OBR, os sensores mais usados são: sensor de luz, sensor de distância por ultrassom, sensor de cor, sensor de posição e deslocamento e bússola digital. O programa feito pelos estudantes analisaram os dados destes sensores e faziam decisões para as próximas ações do robô, tal como ir para frente, desviar de um obstáculo, ou usar uma garra para resgatar a vítima. Em nenhum momento os alunos podem interagir 
com o robô. Após ser ligado, ele deve completar toda missão sem nenhuma intervenção ou comando por controle remoto.

\subsection{Avaliação geral do projeto}

A avaliação do desempenho escolar dos estudantes participantes nesse projeto foi feita tendo como referência as notas do primeiro semestre de 2013, sem a aplicação do projeto, comparado ao segundo semestre do mesmo ano, desta vez com sua execução. Essas notas foram referentes a todas as disciplinas escolares desses estudantes, sendo elas disponibilizadas na direção das escolas.

Por meio das informações obtidas, sendo respectivamente antes e após da execução do projeto, pode-se perceber que houve uma melhora significativa desses alunos, já que aumentaram o índice da média de notas acima de 9,0 em aproximadamente $8 \%$ quando comparado ao período sem a aplicação do projeto. Como consequência dessa melhora, o índice da nota entre 7,0 e 8,0 diminuiu quase $7 \%$ e os índices de notas entre 5,0 e 7,0 diminuíram perto de $1 \%$.

Já pelas informações contidas no questionário, os resultados foram agrupados em uma tabela contendo análises estatísticas e qualitativas relacionadas a cada grupo de perguntas e respostas, contabilizando assim todos os aspectos do trabalho que reflitam de maneira fidedigna aos resultados da pesquisa. O primeiro item questionado foi com relação à avaliação do projeto. Quanto à sua qualidade, que houve uma aprovação considerável por parte do público envolvido, chegando a mais de $80 \%$ dos alunos a opção excelente.

Como consequência do contato desses estudantes com o projeto e a participação nas competições, os seus conhecimentos de na área de algoritmos e em outras disciplinas melhoraram de forma razoável, como citado anteriormente, já que ao início desse projeto eles tinham pouco envolvimento com a disciplina de algoritmos, pois a maioria desses estudantes tinha muita dificuldade para programação. Também foi observado pelos professores que após o projeto dois dos seis estudantes, contabilizado em $33 \%$, melhoraram muito quanto à motivação e ao interesse em sala de aula. Portanto, o progresso observado no desempenho escolar e na melhoria dos conhecimentos da área da computação pelos próprios estudantes, pode estar relacionado à motivação e ao interesse dos estudantes nas aulas, como pode ser observado no resultado anterior, já que esses estudantes que obtiveram bons resultados em seu desempenho escolar também foram as que os alunos ficaram muito motivados.

\section{Conclusão}

Para os estudantes do curso Técnico em Informática envolvidos nesse projeto, a experiência foi recompensadora por desenvolver um projeto que envolve várias disciplinas da área comum e especifica. Além disso, a participação desses alunos no projeto de extensão contribuiu para sua contínua formação e também na articulação dos conhecimentos teóricos e práticos no IFMS. Isso pode ser explicado já que o contato com o LEGO foi uma forma de aprofundar e aplicar os conhecimentos obtidos no IFMS e de despertar o interesse destes alunos para área da robótica educacional. O trabalho de extensão, além de ser gratificante pelo fato dos estudantes satisfazerem as expectativas propostas pelo projeto, também é uma forma de aprender a lidar com questionamentos 
por parte dos estudantes em situações inusitadas tornando o projeto interessante. Entre os pontos positivos do projeto pode-se destacar o interesse e a motivação dos estudantes em se dedicarem mais nas suas disciplinas da área especifica, pois não conseguiam estabelecer um vínculo entre a teoria e prática. Tendo em vista todos estes aspectos, este projeto foi capaz de imprimir e despertar nos estudantes participantes a curiosidade e o gosto pela robótica. No final, os estudantes demonstraram o interesse de continuar o projeto e serem monitores dos novos integrantes. Nesse sentido, o projeto está em andamento, ampliando o número de estudantes envolvidos.

\section{Referências}

Harbour, D.; Hummel, P. Migration of a robotics platform from a freshman introduction to engineering course sequence to a sophomore circuits course. In: Frontiers in Education Conference (FIE), 2010 IEEE. [S.1.: s.n.], 2010. p. F4C-1F4C-6. ISSN 0190-5848.

Khamis, A.; Rodriguez, F.; Salichs, M. Remote interaction with mobile robots. Autonomous Robots, Kluwer Academic Publishers, v. 15, n. 3, p. 267-281, 2003. ISSN 0929-5593. Disponível em: $<$ http://dx.doi.org/10.1023/A\%3A1026268 504593>. Acessado em: 12 de Agosto 2013.

Maher, R. C. et al. Development and Implementation of a Robot-based Freshman Engineering Course. 2005.

Miller, D.; Nourbakhsh, I.; Siegwart, R. Robots for education. In: Siciliano, B.; Khatib, O. (Ed.). Springer Handbook of Robotics . Springer Berlin Heidelberg, 2008. p. 1283-1301. ISBN 978-3-540-23957-4. Disponível em: $<$ http://dx.doi.org/10.1007/978-3-540-30301-556>. Acessado em: 12 de Ago. 2013.

Oliver, J.; Toledo, R.; Valdemarra, E. A learning approach based on robotics in computer science and computer engineering. In: Education Engineering (EDUCON), 2010 IEEE . [S.1.: s.n.], 2010. p. 1343-1347.

Papert, S. Mindstorms: children, computers, and powerful ideas. New York, NY, USA: Basic Books, Inc., 1993. ISBN 0-465-04627-4.

Summet, J. et al. Personalizing cs1 with robots. In: Proceedings of the 40th ACM technical symposium on Computer science education . New York, NY, USA: ACM, 2009. (SIGCSE '09), p. 433-437. ISBN 978-1-60558-183-5. Disponível em: < http://doi.acm.org/10.1145/1508865.1509018>. Acessado em: 12 de Agosto 2013.

Touretzky, D.; Tira-Thompson, E. The tekkotsu "crew": Teaching robot rogramming at a higher level. 2010. Disponível em: https:/www.aaai.org/ocs/index.php/EAAI/EAAI10/paper/view/1952. Acessado em: 12 de Agosto 2013. 